MODOLO, V.A.; TESSARIOLI NETO, J.; ORTIGOZZA, L.E.R. Produção de frutos de quiabeiro a partir de mudas produzidas em diferentes tipos de bandejas e substratos. Horticultura Brasileira, Brasília, v. 19, n. 1, p. 39-42, março 2.001.

\title{
Produção de frutos de quiabeiro a partir de mudas produzidas em dife- rentes tipos de bandejas e substratos ${ }^{1}$.
}

\author{
Valéria A. Modolo; João Tessarioli Neto; Luís Enrique R. Ortigozza \\ ESALQ, C. Postal 9, 13.418-900, Piracicaba - SP. E.mail: vamodolo@carpa.ciagri.usp.br
}

\section{RESUMO}

Com o objetivo de avaliar a produção comercial de frutos de quiabeiro a partir de plantas originadas do transplante de mudas, instalou-se um experimento na ESALQ em Piracicaba. Na produção de mudas, que ocorreu em ambiente protegido, foram utilizados três tipos de bandeja, que diferiam entre si pela altura e volume das células, associadas a quatro diferentes substratos, que eram variações de uma mistura comercial (denominada GII). O delineamento experimental foi de blocos ao acaso, com quatro repetições, no esquema fatorial $3 \times 4$ (três tipos de bandeja e quatro variações do substrato), perfazendo um total de doze tratamentos. Foram transplantadas 30 mudas/tratamento, obedecendo ao espaçamento de $0,5 \times 1,0 \mathrm{~m}$. Cada parcela experimental foi constituída por cinco fileiras de 3,0 m de comprimento totalizando a área de $15 \mathrm{~m}^{2}$. A colheita foi iniciada 49 dias após o transplante, sendo colhidos frutos de tamanho comercial ( $8-10 \mathrm{~cm}$ de comprimento) das doze plantas centrais. Foram avaliados número e peso total dos frutos. Foi observada maior produtividade em plantas originadas de mudas provenientes das bandejas de maior tamanho, independentemente do substrato utilizado. A menor produtividade ocorreu quando no substrato foi adicionado casca de arroz carbonizada na proporção 1:1 ao produto comercial GII, independentemente do tipo de bandeja utilizada.

Palavras-chave: Abelmoschus esculentus, transplante, recipientes, substrato.

\begin{abstract}
Influence of different tray cell sizes and substrates on the production of okra plantlets and fruits.

This study proposed to evaluate the production of okra fields established by using seedling transplant. The experiment was carried out in a greenhouse at the Escola Superior de Agricultura "Luiz de Queiroz" in São Paulo, Brazil. Trays with different cell size were used in the okra seedling production. The substrates used were a blend of a commercial mixture (Gioplanta). A completely randomized block design, with $3 \times 4$ factorial arrangement (3 types of trays and 4 different substrates) was used, in a total of 12 treatments. In the field 30 seedlings per each treatment were transplanted using $1,0 \mathrm{~m}$ between rows and $0,5 \mathrm{~m}$ within each plant in the row. Each plot was constituted by 5 rows of $3,0 \mathrm{~m}$ and area of $15 \mathrm{~m}^{2}$. Commercial fruits size ( $8-10 \mathrm{~cm}$ length) were harvested from the 12 central plants 49 days after seedling transplanting. Number and fruit weight were evaluated. In the field the plants grown in largest cell volume produced more fruits than plants from small cell volume, regardless of the substrate. The lowest yield was obtained when GII and carbonized rice hulls were mixed (1:1) in the seedling production, independently of the tray type used.
\end{abstract}

Keywords: Abelmoschus esculentus, transplant, container, substrate.

(Aceito para publicação em 19 de janeiro de 2.001)

$\mathrm{O}$ cultivo do quiabeiro (Abelmoschus esculentus (L.) Moench) é realizado predominantemente, por meio de semeadura direta, onde são colocadas de quatro a cinco sementes/cova (Minami et al., 1997) ou até mesmo de cinco a oito, conforme as recomendações técnicas para o Estado de São Paulo (Jorge et al., 1990), consumindo assim de 4 a $8 \mathrm{~kg}$ de sementes/ha. Este gasto excessivo de sementes deve-se ao fato destas apresentarem dormência devido à impermeabilidade do tegumento (Medina, 1971), que promove uma germinação desuniforme e demorada. Este fato é acentuado quando a semente pos- sui menos de $12 \%$ de umidade relativa, o que pode ocorrer quando é submetida a um período de secagem muito prolongada ou armazenamento em local com umidade relativa inferior a $60 \%$ (Minami et al., 1997). Outro fator importante no início do cultivo é a exigência de temperaturas elevadas, pois a tem-

${ }^{1}$ Parte da dissertação de mestrado do primeiro autor, ESALQ/USP, Piracicaba - SP. 
peratura ótima para germinação das sementes é de 21 a $35^{\circ} \mathrm{C}$ (Sementes Hortec, 1995). Dependendo da região estas condições ocorrem somente em algumas épocas do ano, o que restringe a época de plantio da cultura.

A produção de mudas pode ser uma alternativa quando as sementes de uma determinada espécie ou variedade são menos vigorosas e necessitam de maiores cuidados na fase de germinação e emergência (Minami, 1995).

Existem no mercado diversos modelos de bandejas de isopor com células de formas e volumes diferentes, com profundidades de 47, 60 ou $120 \mathrm{~mm}$. Do mesmo modo, estão disponíveis várias formulações de substratos, produzidos especialmente para a produção de mudas olerícolas. Porém, o estudo do volume e da altura adequada do recipiente, assim como do substrato para cada espécie é de grande importância para que não ocorram prejuízos no desenvolvimento da cultura após o transplante, bem como na sua produção.

Estudos realizados por Ruff et al. (1987) mostraram que houve redução no desenvolvimento e alterações na morfologia do sistema radicular de plantas de tomate quando estas foram produzidas em diferentes tipos de recipiente. Weston \& Zandstra (1986), avaliaram diversos tamanhos de bandejas na produção de mudas de tomate e verificaram que após o transplante das mudas para o campo, plantas provenientes de mudas formadas em bandejas com célula de maior volume começavam a produzir mais cedo que aquelas provenientes de células de menor volume, não havendo porém diferença entre as produções totais. Isto foi atribuído ao menor trauma sofrido pelas raízes durante o transplante, pois as plantas originadas de células maiores apresentavam sistema radicular mais desenvolvido. Em berinjela, além da precocidade de produção, houve diferença na produtividade pois as mudas provenientes de células maiores apresentaram aumento na produção (Gorski \& Wertz, 1985). Nicklow \& Minges (1963) e Knavel (1965) verificaram que mudas provenientes de células de maior volume apresentavam mais folhas, maior taxa de desenvolvimento após o transplante e preco- cidade na produção. Verifica-se portanto, que a interferência do tamanho do recipiente na produtividade pode variar de acordo com a hortaliça considerada.

O objetivo deste experimento foi avaliar a produção de frutos de quiabeiro a partir de mudas produzidas em três tipos de bandejas e quatro tipos de substrato.

\section{MATERIAL E MÉTODOS}

O experimento foi conduzido na Escola Superior de Agricultura "Luiz de Queiroz". Para a produção de mudas de quiabeiro cultivar Santa Cruz - 47, em ambiente protegido, foram utilizadas bandejas de isopor de três tipos: T1 (72 $\mathrm{cm}^{3}$ de volume, $12 \mathrm{~cm}$ de altura e 128 células); T2 $\left(36 \mathrm{~cm}^{3}\right.$ de volume, $6 \mathrm{~cm}$ de altura e 128 células) e T3 $\left(16 \mathrm{~cm}^{3}\right.$ de volume, 4,7 cm de altura e 200 células), associadas a quatro substratos constituídos basicamente de uma formulação comercial, denominada pelo fabricante como GII (Gioplanta - Comércio e Representação Agrícola Ltda.) e composto pela mistura de casca de pinus compostada, casca de arroz carbonizada, vermiculita grossa número doze, calcário dolomítico e uma adubação básica composta por fertilizante 4-148, FTE-BR9 e Superfosfato Simples. Nesta formulação foram feitas diferentes associações com outros materiais e/ ou com suplementação de adubação. $\mathrm{O}$ substrato denominado A foi composto somente da formulação do fabricante. Para aquele denominado B, na formulação do fabricante foram acrescentadas suplementações minerais durante a formação da muda. Para o substrato $\mathrm{C}$ foi encomendado ao fabricante o produto GII sem a adubação básica e também foram realizadas as suplementações minerais, semelhante ao substrato B. No substrato D foi adicionada casca de arroz carbonizada na proporção $1: 1$ ao produto comercial GII e suplementação mineral durante a formação da muda. Estas suplementações adotadas nos substratos B, C e D consistiram da aplicação de $300 \mathrm{ml} /$ bandeja do adubo solúvel Petters, na concentração $1 \mathrm{~g} / \mathrm{l}$ em intervalo de 6 dias. A composição de elementos deste adubo é: $20 \% \mathrm{~N} ; 10 \%$ $\mathrm{P} ; 20 \% \mathrm{~K} ; 0,15 \% \mathrm{Mg} ; 0,02 \% \mathrm{~B} ; 0,01 \%$
$\mathrm{Cu} ; 0,1 \% \mathrm{Fe} ; 0,056 \% \mathrm{Mn} ; 0,01 \%$ Mo e $0,0162 \% \mathrm{Zn}$.

A semeadura ocorreu em 09/02/1997 e o transplante das mudas após 31 dias, adotando-se o espaçamento de $0,5 \mathrm{~m}$ entre plantas e 1,0 m entre linhas. Segundo Vidal-Torrado \& Sparovek (1993), o solo desta área é descrito como Terra Roxa Estruturada Eutrófica A moderado textura argilosa sobre muito argilosa, correspondente ao Kandiudalfic Eutrudox.

Nas primeiras semanas após o transplante, a irrigação por aspersão foi realizada quase que diariamente e após o pegamento das mudas no campo estas foram realizadas em intervalos maiores (duas a três vezes por semana). A adubação de cobertura foi realizada aos 30 e 60 dias após o transplante, empregando-se $10 \mathrm{~g} /$ planta de nitrocálcio. Efetuou-se o controle de pragas e doenças conforme necessário e para o controle de plantas daninhas foram realizadas capinas manuais, com intervalo de aproximadamente quinze dias, durante todo o ciclo da cultura.

O delineamento experimental foi blocos ao acaso no esquema fatorial $3 \mathrm{x}$ 4. Os tratamentos consistiram da combinação dos quatro diferentes substratos (A, B, C e D) aos três tipos de bandeja (T1, T2 e T3). Cada parcela foi composta por 30 mudas numa área de $15 \mathrm{~m}^{2}$ (5 fileiras com 6 plantas). Como área útil foram consideradas as doze plantas centrais desprezando-se as linhas laterais como bordadura. Os critérios de avaliação foram número e peso total dos frutos por planta.

Foram efetuadas sete colheitas sendo a primeira aos 49 dias após o transplante das mudas para o campo, quando os frutos apresentavam padrão comercial, ou seja, 8 a $10 \mathrm{~cm}$ de comprimento.

Os frutos de cada parcela foram contados e pesados em balança de precisão e as médias foram comparadas pelo Teste de Tukey ao nível de 5\% de probabilidade, de acordo com Gomes (1990). $\mathrm{Na}$ análise dos dados utilizou-se o programa computacional SAS (Statistical Analysis System Institute, 1985).

\section{RESULTADOS E DISCUSSÃO}

As plantas originadas das mudas provenientes das bandejas com células de maior volume (T1 e T2), produziram 
maior quantidade de frutos que aquelas provenientes de bandeja com células de menor volume (T3), independentemente do substrato utilizado (Tabela 1). As mudas produzidas na bandeja com células de volume intermediário (T2) não diferiram daquelas produzidas nas demais bandejas. O mesmo comportamento que ocorreu com a produção em número de frutos foi verificado também para a produção em peso (Tabela 2 ). Estes resultados estão em concordancia com aqueles obtidos por Gorski \& Wertz (1985) em berinjela, onde também houve diferença na produção de frutos quando as mudas transplantadas eram provenientes de bandejas com células de maior volume. Weston \& Zandstra (1986), não observaram este comportamento na cultura do tomate. Estes autores constataram que as plantas provenientes de bandejas cujo volume de célula era maior começaram a produzir mais cedo, entretanto, não diferiram na produção total. Sendo assim, a interferência do tamanho do recipiente na produtividade pode variar de acordo com a hortaliça.

É importante ressaltar que antes do transplante, ao se comparar os doze tipos de mudas estudadas, constatou-se que aquelas produzidas na bandeja de maior volume celular (T1) apresentaram maior desenvolvimento. É possível que estas mudas pudessem ter sido transplantadas mais cedo, considerando-se que após o transplante houve um certo índice de tombamento que pode ser devido ao tamanho da muda no momento do transplante.

Quanto aos substratos pode-se observar que aquelas mudas formadas utilizando casca de arroz carbonizada, na proporção $1: 1$, originaram plantas que produziram menor quantidade em peso e em número de frutos, independentemente do tipo de bandeja (Tabelas $1 \mathrm{e}$ 2). Também foi observado que além do substrato $\mathrm{D}$ ter proporcionado mudas de menor tamanho, no momento do transplante houve dificuldade na retirada destas mudas das bandejas, pois não houve formação de torrão. Os demais substratos não diferiram entre si.

Como informação complementar, observou-se que o sistema de produção de mudas em bandeja, de uma forma geral, possibilita maior uniformidade de germi-

Tabela 1. Número total de frutos/planta de quiabeiro, referentes às mudas formadas em diferentes tipos de bandejas e substratos. Piracicaba, ESALQ, 1997.

\begin{tabular}{lcccc}
\hline Substratos $^{2}$ & \multicolumn{3}{c}{ Bandejas $^{1}$} & \multirow{2}{*}{ Média $^{3}$} \\
\cline { 2 - 4 } & T1 & T2 & T3 & \\
\hline A & 55,66 & 50,05 & 42,63 & $48,45 \mathrm{a}$ \\
B & 58,16 & 43,86 & 41,50 & $47,84 \mathrm{a}$ \\
$\mathrm{C}$ & 50,95 & 54,66 & 44,89 & $50,17 \mathrm{a}$ \\
$\mathrm{D}$ & 43,00 & 36,14 & 34,99 & $38,04 \quad \mathrm{~b}$ \\
\hline Média $^{3}$ & $51,19 \mathrm{~A}$ & $46,18 \mathrm{AB}$ & $41,00 \mathrm{~B}$ & \\
\hline
\end{tabular}

${ }^{1} \mathrm{~T} 1, \mathrm{~T} 2, \mathrm{~T} 3$ : bandejas com 128 células e $72 \mathrm{~cm}^{3}$ de volume; 128 células e $36 \mathrm{~cm}^{3}$ de volume e 200 células e $4,7 \mathrm{~cm}^{3}$ de volume, respectivamente.

${ }^{2}$ A, B, C e D: substratos compostos pela formulação GII; formulação GII + suplementação mineral; formulação GII sem adubação básica do fabricante + suplementação mineral; formulação GII + casca de arroz carbonizada na proproção 1:1 + suplementação mineral, respectivamente.

${ }^{3}$ Médias seguidas por letras diferentes, maiúscula na linha e minúscula na coluna, diferem entre si pelo teste de Tukey a $5 \%$.

$\mathrm{CV}=14,45 \%$

Tabela 2. Produção total (em gramas), de frutos/planta de quiabeiro referentes às mudas formadas em diferentes tipos de bandejas e substratos. Piracicaba, ESALQ, 1997.

\begin{tabular}{lcccc}
\hline Substratos $^{2}$ & \multicolumn{3}{c}{ Bandejas $^{1}$} & \multirow{2}{*}{ Média $^{3}$} \\
\cline { 2 - 4 } & T1 & T2 & T3 & \\
\hline A & 819,79 & 921,42 & 727,22 & 822,80 a \\
B & 927,03 & 686,29 & 661,94 & 758,42 a \\
C & 831,42 & 884,94 & 700,23 & 805,53 a \\
D & 683,69 & 598,60 & 565,58 & $615,96 \quad$ b \\
\hline Média & $815,48 \mathrm{~A}$ & $772,81 \mathrm{AB}$ & $663,74 \mathbf{B}$ & \\
\hline
\end{tabular}

${ }^{1} \mathrm{~T} 1$, T2, T3: bandejas com 128 células e $72 \mathrm{~cm}^{3}$ de volume; 128 células e $36 \mathrm{~cm}^{3}$ de volume e 200 células e $4,7 \mathrm{~cm}^{3}$ de volume, respectivamente.

${ }^{2} \mathrm{~A}, \mathrm{~B}, \mathrm{C}$ e D: substratos compostos pela formulação GII; formulação GII + suplementação mineral; formulação GII sem adubação básica do fabricante + suplementação mineral; formulação GII + casca de arroz carbonizada na proproção 1:1 + suplementação mineral, respectivamente.

${ }^{3}$ Médias seguidas por letras diferentes, maiúscula na linha e minúscula na coluna, diferem entre si pelo teste de Tukey a 5\%.

$\mathrm{CV}=16,91 \%$

nação, diminuindo assim os problemas de dormência das sementes de quiabeiro.

\section{LITERATURA CITADA}

GOMES, F.P. Curso de estatística experimental. $13^{\mathrm{a}}$ ed. São Paulo: Nobel, 1990. 467 p.

GORSKI, S.F.; WERTZ, M.K. Eggplant and tomato: a study on the effects of transplant root volume on yield. Ohio State University, 1985. (Circ., 288).

JORGE, J.A.; LOURENÇÃO, A.L.; ARANHA, C. (Ed) Instruções Agrícolas para o Estado de São Paulo. 5 ed. Campinas: Instituto Agronômico, 1990. 233 p. (IAC. Boletim Técnico 200).

KNAVEL, D.E. Influence of container, container size and spacing on growth of transplant and yields in tomato. Proceedings of the American Society for Horticultural Science, v. 86, p. 583586, 1965.
MEDINA, P.V.L. Efeito da profundidade de plantio, tipo de leito, modo de semeadura e pré-tratamento na germinação do quiabeiro (Hibiscus esculentus L.). Viçosa: Universidade Federal de Viçosa, 1971. 42 p. (Tese mestrado).

MINAMI, K. Produção de mudas de alta qualidade. São Paulo: T.A. Queiroz, 1995. 128 p.

MINAMI, K.; MODOLO, V.A.; ZANIN, A.C.W.; TESSARIOLI NETO, J. Cultura do quiabeiro: técnicas simples para hortaliça resistente ao calor. Piracicaba: ESALQ/DIB, 1997. 36 p. (Séria Produtor Rural, 3).

NICKLOW, C.W.; MINGES, P.A. Plant growing factors infuencing the field performance of the Fireball tomato variety. Proceedings of the American Society for Horticultural Science, $\mathrm{v}$. 50, n. 2, p. 261-266, 1963.

RUFF, M.; KRIZEK, D.; MIRECKI, R.; INOUYE D. Restricted root zone volume: Influence on growth and development of tomato. Journal of the American Society for Horticultural Science, v. 112, n. 5, p. 763-769, 1987. 
SAS INSTITUTE. SAS user's guide: statistics. $5^{\mathrm{a}}$ ed. Cary, 1985. 958p.

SEMENTES HORTEC. Catálogo de sementes de hortaliças. São Paulo, 1995. 47p.
VIDAL-TORRADO, P.; SPAROVEK, G. Mapa pedológico detalhado do Campus "Luiz de Queiroz”, ESALQ/USP. Piracicaba: ESALQ, 1993. Escala 1:10.000.
WESTON, L.A.; ZANDSTRA, B.H. Effect of root container size and location of production on growth and yield of tomato transplant. Journal of the American Society for Horticultural Science, v. 111, n. 4, p. 498-501, 1986. 